\title{
A STUDY OF GROWTH PROMOTION IN CHILDREN
}

BY

\author{
DOUGLAS HUBBLE and DUNCAN R. MACMILLAN \\ Department of Paediatrics and Child Health, University of Birmingham
}

(RECEIVED FOR PUBLICATION MAY 29, 1962)

Androgens have been used for many years to promote growth in children. Many therapists have either discarded them or have used them only on selected patients who have been carefully observed during the period of treatment. The well-justified dislike of paediatricians and endocrinologists for these drugs has depended, not only on the production of virilism, but more particularly on the advancement of skeletal maturation which they produce. If the acceleration of epiphyseal development advances coincidentally with the acceleration of height no certain good has been achieved as a result of therapy. Although such treatment may have justified itself in individual patients by improved confidence, nutrition or musculature, yet all that has been done, in a biological sense, is to anticipate the pubertal growth spurt. If skeletal maturation has been advanced to a greater degree than height then harm will result because of the earlier fusion of the epiphyses. The therapist has purchased an immediate credit at the price of future insolvency.

Physicians who have the care of these short children have naturally been interested in the new testosterone derivatives that are claimed to have a heightened effect on protein anabolism and a reduced androgenic effect. Bongiovanni (1961) has recently reviewed the indications for the use of these new protein anabolic agents in accelerating growth in children, and he states a conservative opinion of their value with which we cordially agree. He writes, 'the earliest clinical studies must be regarded with caution; it may be several years before the first optimistic reports can be accepted with assurance'. The need for this warning has been quickly demonstrated. One group of workers (Reilly and Gordan, 1961) reported that fluoxymesterone produced an average growth in 16 short children of $3 \cdot 2$ in. $(8 \cdot 1$ $\mathrm{cm}$.) a year [average growth 1.9 in. $(5 \cdot 8 \mathrm{~cm}$.) a year before treatmentl while the average advancement in skeletal maturation was 0.83 years: the drug, therefore, showed a clear profit in the promotion of growth as against the development of the skeleton. Other investigators (Mellman, Bongiovanni and Hope, 1959) subsequently reported a small double blind study of 17 children of average height, divided into three groups: the first group was treated with fluoxymesterone ( $2 \mathrm{mg}$. daily); the second with methyl testosterone (10 mg. daily) and the third with a placebo. They concluded that while fluoxymesterone may be more effective than methyl testosterone in promoting growth, it has an effect on skeletal maturation equal to that of methyl testosterone. It is now generally recognized that in making the final assessment of the effect of a drug on skeletal advancement it is necessary to examine radiographs taken not less than six months after the period of treatment is complete. While this period of precaution was observed in the second investigation, there is no clear indication in the first report that attention was paid to it.

In this investigation we have used methandienone (1-dehydro-17-methyltestosterone; 'dianabol') which differs from methyl testosterone only in having a double bond between carbon 1 and 2 in the $A$ ring of the steroid nucleus. Liddle and Burke (1960) state that methandienone has $\mathbf{1 0}$ times the nitrogenretaining effect of methyl testosterone, and Wynn and Landon (1961) have shown that it produces marked nitrogen retention in doses of $0 \cdot 2-0 \cdot 4 \mathrm{mg}$. $/ \mathrm{kg}$. body weight per day, i.e. $15-30 \mathrm{mg}$. for the average-sized woman. Although Wynn and Landon report that the virilizing effects of the drug were 'slight' or 'absent' in their 30 male and female patients they do in fact record a considerable endocrine effect. In the four pre-menopausal women who had regular menses before the drug was taken amenorrhoea developed in all, and in the four older women who had menopausal symptoms when the drug was started, these symptoms were relieved. Schärer, Habich and Prader (1960) used 1-dehydromethyltestosterone to promote growth in children, and some of their conclusions are similar to those reported by us below. The relevant animal experiments were made by Desaulles, Krähenbühl, Schuler and Bein (1959) who reported that in the rat methyltestosterone was 30 times more active than methandienone in the inhibition of the oestrous cycle. It is apparent that the anterior pituitary 
TABLE

ANALYSIS OF EFFECTS OF METHANDIENONE THERAPY ON HEIGHT AND SKELETAL MATURATION IN 23 CHILDREN

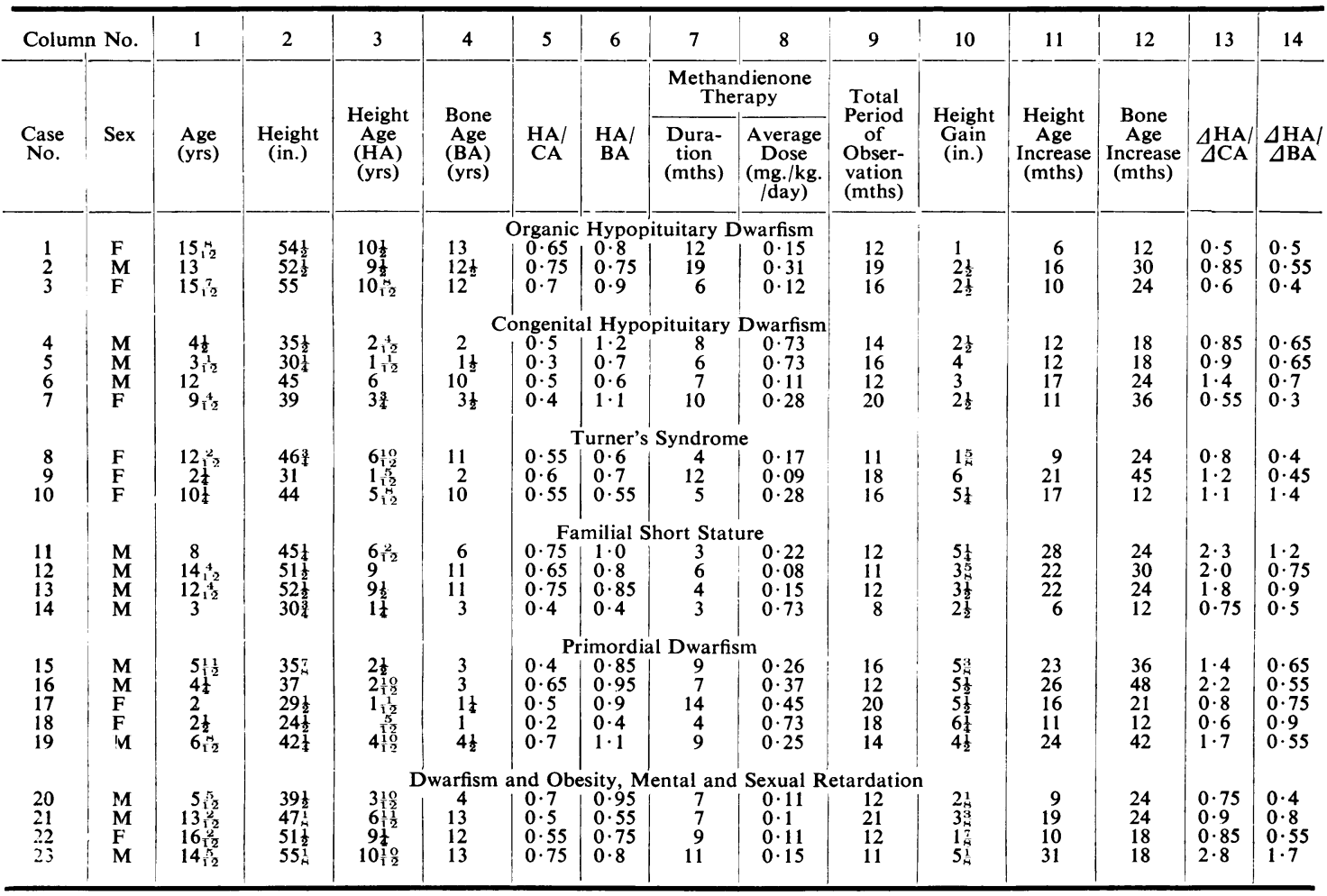

hormones of man, through which it must be assumed the endocrine effects are mediated, are more susceptible to the depressive effect of methandienone than is the pituitary of the rat.

It becomes apparent, too, that these protein anabolic drugs have complicated actions (nitrogen retaining, virilizing and endocrine) and interactions. We know little of the mechanisms involved and these considerations also encourage a conservative attitude in their use.

\section{The Patients}

We report here the use of methandienone to promote growth in 23 children who were below the third percentile for height. They were diagnosed as suffering from organic hypopituitarism (Cases 1, 2 and 3), from congenital hypopituitarism (Cases 4, 5, 6 and 7), from Turner's syndrome (Cases 8,9 and 10), from familial short stature (Cases 11, 12,13 and 14), from primordial dwarfism (Cases $15,16,17,18$ and 19), and from dwarfism, obesity, mental and sexual retardation (Cases 20, 21, 22 and 23). Although the data in regard to height and skeletal development are given in the Table we give here a brief statement of our diagnostic criteria in the various groups.

Organic Hypopituitarism. These three children all showed dwarfism, sexual retardation, and some degree of adrenocortical and thyroid deficiency. Cases 1 and 2 showed calcification in the sella turcica, and Case $3 \mathrm{had}$ an operation at 8 years for removal of a chromophobe adenoma.

Congenital Hypopituitarism. These four children - three boys and one girl-had the necessary clinical criteria for this presumptive diagnosis, i.e. normal length and weight at birth, growth failure noticed first during the second or third year of life, immaturity of bony facies, hypercholesterolaemia (except Case 6) despite the lack of any evidence of hypothyroidism.

Turner's Syndrome. Cases 8 and 9 had a sex chromosomal complement of XO, Case 10 of $\mathrm{XO}, \mathrm{XX}, \mathrm{XXX}$. Case 10 is now pubertal. 
Familial Short Stature. All of these children came of families of whom one or more members were well below the third percentile for height. Case 14 was atypical, his father is 59 in. $(149.8 \mathrm{~cm}$.) in height and has a disproportionately large skull as does his son, our patient. In the other three children the bone age was retarded-these children may well be 'late maturers'.

Primordial Dwarfism. These five children all weighed less than $4 \frac{1}{2} \mathrm{lb}$. $(2.04 \mathrm{~kg}$.) at birth despite full gestation and the birth lengths were $18 \mathrm{in}$. $(45.72 \mathrm{~cm}$.) or less in the three children in which this measurement was recorded (intrauterine growth retardation). They do not comprise a single clinical group, however, since one has hypoglycaemia, three have minor skeletal abnormalities and two are mentally retarded.

Obesity, Mental and Sexual Retardation and Short Stature. This clinical description defines a group which is probably of multiple pathogenesis.

\section{Methods}

Dosage. The doses of methandienone used are detailed in the Table. They varied from $0.08 \mathrm{mg}$./ kg./day to $0.73 \mathrm{mg}$./kg./day.

Course of Treatment. All patients were given an initial course of treatment of three months' duration. Therapy was continued if there was no evidence of virilization and no appreciable advance in bone age at the end of this time. Patients continuing on methandienone were examined at intervals of one to three months, and skeletal maturation was determined every three months. Virilization other than slight hypertrophy of the phallus, and skeletal maturation proceeding at a rate obviously faster than the rate of growth, were regarded as indications for stopping treatment. After cessation of therapy the height and skeletal maturation were determined at three-monthly intervals. Two patients (Cases 3 and 18) received short second courses of methandienone following regression of the signs of virilization that had required the termination of the first course of treatment.

Records. The charts for height and weight in both sexes prepared by J. M. Tanner and R. H. Whitehouse (University of London, Institute of Child Health, for The Hospital for Sick Children, Great Ormond Street, London) were used to record the serial measurements in these children. They were also used to estimate 'height age', referring the measured height of the patient to the 50 percentile measurement on the chart, and reading the relevant age (e.g. a height of $40 \mathrm{in} .(101.6 \mathrm{~cm}$.) is on the 50 percentile for 4 years and the height age of the patient is therefore 4 years). This useful convention has been criticized and has obvious limitations.

Skeletal Maturation. There are many pitfalls awaiting investigators who use radiographs to assess skeletal maturation and its response to treatment, and much attention has been paid to them in the literature. We have already commented on the need to make a final assessment at least six months after treatment has been completed. The observer error has been well documented (Mainland, 1953). There are wide variations in the rate of skeletal development in normal children, and occasionally between different sites in the same child (Mellman et al., 1959). We refer below to the difficulty caused by the carpal bones appearing in an irregular order. We have limited our assessment to the bones of the hand and wrist, and matched them with the Greulich and Pyle Atlas (1959). We have assessed these films independently, and in the few assessments in which we differed we have arrived at an agreed opinion. The fact that our conclusions have depended on repeated serial examinations will have reduced to some extent the inherent uncertainties of such findings. We have employed the usual description of 'bone-age', although this convention cannot, for example, distinguish the normal 'late maturer' from the abnormally retarded child. We have not reported our results in terms of the alteration in predictable height (Bayer and Bayley, 1959). These tables do not apply to children with skeletal maturation below the six-year level, and the prediction of height in children whose growth is abnormal must give these calculations an additional fallibility (Table).

The period of treatment and the follow-up period are included together in the total period of observation (column 9). The period of follow-up was six months ( \pm 1 month) unless there was evidence of accelerated growth or skeletal maturation continuing beyond this period (Cases 5,10 and 11). Treatment was continued in the follow-up period in Cases 1 and 2. The final examination was at 8 and 10 months after stopping treatment in Cases 7 and 13. Case 23 has not been available for a follow-up examination to date. The age (column 1), and height (column 2), the height age (column 3) and the bone age (column 4) are as recorded at the beginning of treatment. Although there were available in many cases records of height and 
skeletal maturation going back some time we have not used them to compare our results with pretreatment rates, since they were not available in all patients. Column 5 gives the ratio of height age to chronological (actual) age; all of these values are below unity indicating varying degrees of dwarfism. Column 6 gives the ratio of height age to bone age; in all but four of our patients (Cases 4, 7, 11 and 19) this ratio was below unity indicating that in 19 patients the height was more retarded than skeletal maturation. Column 13 gives the ratio of the advance in height age to the advance in chronological age, and column 14 gives the ratio of the advance in height age to the advance in bone age during the period of treatment and follow-up. The responses to methandienone of the 23 patients are plotted in Fig. 1 according to $\triangle \mathrm{HA}: \triangle \mathrm{CA}$ and $\mathrm{HA}: \mathrm{BA}$ ratios. Values for $\triangle \mathrm{HA} / \Delta \mathrm{CA}$ are grouped into three categories: (i) less than the original value for $\mathrm{HA} / \mathrm{CA}$; (ii) less than unity but greater than original HA/CA; (iii) unity and above. A similar grouping is made for $\triangle \mathrm{HA} / \Delta \mathrm{BA}$.

\section{Analysis of Results}

Comparison of the increments in height age in months (column 11) to the corresponding advances in chronological age (column 9) and bone age (column 12) indicates the response to therapy in each patient. These relations are expressed as ratios in columns 13 and 14 . Where the increase in height age is equal to or greater than the increase in chronological age $(\Delta \mathrm{HA} / \Delta \mathrm{CA} \equiv>1)$ growth has occurred at a rate at least as rapid as that of normal children of the same height. Similarly, where the increase in height age is equal to or greater than the increase in bone age $(\Delta \mathrm{HA} / \Delta \mathrm{BA} \equiv>1)$ the height gain for each year of skeletal maturation has been comparable to that of normal children on the 50th percentile.

Where values for $\Delta \mathrm{HA} / \Delta \mathrm{BA}$ are below unity, a comparison with the pre-treatment values for HA/CA and HA/BA is useful, as these ratios reflect the child's previous rate of growth and previous height increment per year of skeletal maturation.

As summarized in the Figure, three cases (Cases 10, 11 and 23) showed an increase in height age greater than both the increase in chronological age and the increase in bone age $(\Delta \mathrm{HA} / \Delta \mathrm{CA}$ and $\Delta \mathrm{HA} / \Delta \mathrm{BA}$ both greater than unity). Unquestionably, these cases have had a good response to therapy for they have grown faster than do comparable children and their potential ultimate height may have been increased. Three more (Cases 6,12 and 13) had an equally good growth response but the advance in skeletal maturation, though no greater than

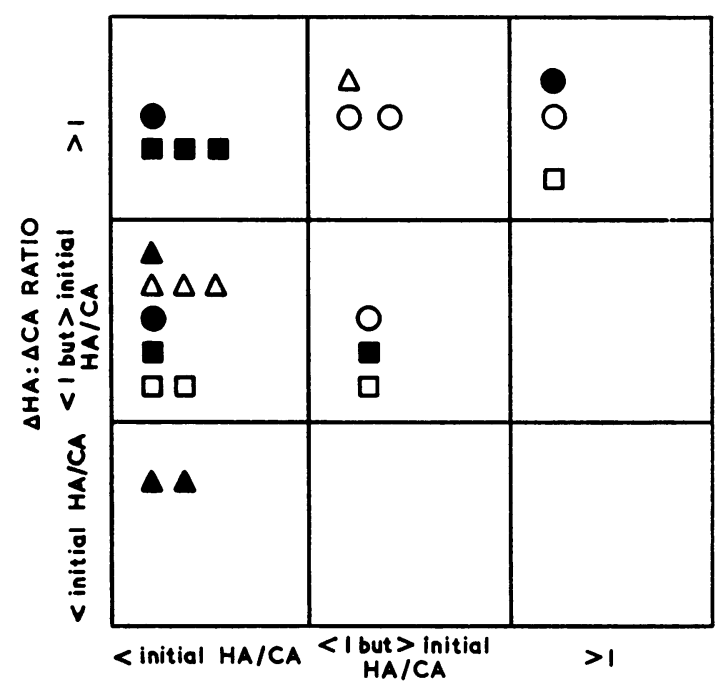

$\triangle H A: \triangle B A$ RATIO

FIGURE.-Distribution of therapeutic responses of 23 short children treated with methandienone.

A organic hypopituitary dwarfism; $\Delta$ congenital hypopituitary dwarfism; Turner's syndrome; O familial short stature; primordial dwarfism; $\square$ dwarfism with obesity, mental and sexual retardation.

before treatment, makes an increase in ultimate height improbable. In four (Cases 9, 15, 16 and 19) satisfactory acceleration of growth was offset by a degree of skeletal maturation which suggested that ultimate height had been compromised $(\Delta \mathrm{HA} / \Delta \mathrm{BA}$ less than pre-treatment HA/BA).

In three cases (Cases 14, 18 and 21) the changes in height age relative to both chronological age and bone age, though more favourable than before treatment, were not sufficient to claim any therapeutic advantage though certainly no harm had been done.

In the remaining 10 (Cases $1,2,3,4,5,7,8$, 17,20 and 22) growth stimulation was slight or absent and skeletal maturation was accelerated so that potential ultimate height was presumably decreased. Theoretically it must be considered that harm has been done to these children but it should be noted that six of them are hypopituitary dwarfs. In these children the prognosis for future growth without treatment is poor, so a sacrifice of apparent growth potential may be justifiable if the growth rate can be increased (see below).

For the whole group of 23 children the average growth rate during treatment was $1 \cdot 2(\Delta \mathrm{HA} / \Delta \mathrm{CA})$. This compares with the overall rate before treatment (as inferred from the initial value for HA/CA) of 0.6 . The average ratio of advance in height age to advance in bone age $(\Delta \mathrm{HA} / \Delta \mathrm{BA})$ was 0.7 and the average initial ratio for HA/BA was $0 \cdot 85$. 
This suggests that in these children, considered as a group, there was some reduction of their growth potential.

\section{Responses of Various Groups}

When we started this inquiry we hoped that it might indicate in which groups of children with retarded growth the use of a protein anabolic drug would be useful. We also hoped that its use might facilitate diagnosis in a field in which the criteria for an aetiological classification are woefully inadequate. For example, do children suffering from hypopituitarism in whom a defective output of growth hormone may be assumed obtain the expected response to a protein anabolic drug? And do children in whom there is genetic resistance to growth respond to the drug? And do the children whose growth was defective in intrauterine life respond to the action of a protein anabolic agent?

The answers given to these questions are at best tentative and we certainly cannot conclude that the use of the drug will facilitate diagnosis. But there are differences in the growth response to methandienone between the various groups, and occasionally the response in an individual patient is atypical for the group so that some doubt is thrown on the accuracy of the original diagnosis.

The growth response in patients suffering from hypopituitarism, whether organic or congenital, was the least satisfactory. Generally in this group treatment accomplishes no more than the maintenance of growth parallel to the third percentile (but at a distance below it varying from 5 to $10 \mathrm{in}$.) $(12 \cdot 7-25 \cdot 4 \mathrm{~cm}$.). This has been the experience of one of us in treating such children with varying doses of these weak androgens over many years. These drugs are clearly no substitute for the growth hormone. However, if these children are not treated the gap between their growth curve and the third percentile for height steadily deepens.

If Case 6 maintains his high $\Delta \mathrm{HA} / \Delta \mathrm{CA}$ ratio under continued treatment he is clearly atypical for this group. In all but one other respect he is a characteristic example of congenital hypopituitarism. His birth weight was $7 \mathrm{lb}$. (3.17 kg.) and he grew normally until the third year of life since when his growth has averaged little more than 1 in. $(2 \cdot 54 \mathrm{~cm}$.) a year. As is shown on the Table his height at the age of 12 years was 45 in. $(114 \cdot 3 \mathrm{~cm}$.) (height age 6 years) and his bone age was 10 years. He had a characteristically immature facies; his intelligence was good; the genitalia were within average limits for his height; the right testis was retracted, the left was in the scrotum. The sella turcica was not enlarged and all other tests of endocrine function gave normal values. There was no elevation of the serum cholesterol such as one of us (Hubble, 1957) has described in hypopituitarism, whether or not there is an associated hypothyroidism. This was the only other finding which casts doubt on the original diagnosis.

In the two patients with classical Turner's syndrome (Cases 8 and 9) the effect of the drug was markedly virilizing despite the small doses employed. Marked skeletal maturation accompanied growth stimulation in both cases. We speculate that the tendency to virilization in these patients may depend on the lack of oestrogen or the absence of an X chromosome.

Although the three children (Cases 11, 12 and 13) are classified as familial short stature, for which there was adequate family history, they also showed skeletal retardation and might equally be regarded as 'late maturers'. The history of Case 11 is as follows. His father was $5 \mathrm{ft} .6$ in. $(167.6 \mathrm{~cm}$.) in height and his mother $5 \mathrm{ft} .1$ in. $(154.9 \mathrm{~cm}$.). His height and bone age were synchronous at 6 years, while his actual age was 8 years. He was given treatment for three months only, but the response was dramatic. He grew $5 \cdot 25$ in. $(13 \cdot 3 \mathrm{~cm}$.) in the year's period of observation. His bone age advanced two years in this period; one year's advance occurred during the period of from four to nine months after therapy was stopped. Such an experience emphasizes the need for a long period of observation before the final assessment of skeletal maturation is made. The drug has obviously given this boy a pubertal growth spurt. His muscles have thickened, his facial development has matured, and his confidence markedly increased - a response to therapy gratifying to the boy, his parents and his doctors.

The fourth patient in this group (Case 14), although undoubtedly suffering from familial short stature has inherited an undefined osseous disorder from his father.

The patients with primordial dwarfism (Cases 15-19) show a well-differentiated response inside their group. Cases 15, 16 and 19 show a good growth response to treatment and Cases 17 and 18 a poor response. In all these patients the HA/BA ratio worsened as a result of therapy, but the initial assessment of the bone age may have been too low in Cases 15 and 19, owing to absence of ossification of the lunate and triquetrum which rapidly appeared after treatment was begun. It is now our impression that the bones of the hand give a better indication of skeletal maturation than does the carpus, and that discordant carpal centres should be ignored in the assessment of bone age.

Treatment may well be justified in children such as Cases 15, 16 and 19 who have a retarded skeletal 
maturation. Cases 15 and 19 are now approximately on the 25 percentile for height and their bone age is little, if at all, advanced for their chronological age.

The group of children with dwarfism, obesity, mental and sexual retardation also display a differing pattern of response, possibly implying a different aetiology within the group. In all of them the dosage of the drug was small yet in three of them there was a considerable advance in skeletal maturation. In three (Cases 20, 21 and 22) the growth response was fair and in the fourth (Case 23) exceptionally good, the result equalling that in Case 11 , although his period of observation is not yet complete.

\section{Discussion of Results}

In the dosage in which the drug was used in this trial a satisfactory growth response was obtained in 10 out of the 23 children treated. We have employed the drug in the smaller dosage recommended by Liddle and Burke (1960) $(0.05 \mathrm{mg} . / \mathrm{kg}$./ day) in a group of children not reported here and the effect on growth has not been striking and virilization has occasionally been observed. Whether when the androgenic quality of the drug is so reduced any useful effect on growth remains (due to the nitrogen-retaining properties of the drug) is a matter not yet decided, but worth decision, and we propose to continue its use in this small dosage. It must be remembered that 13 of our children when given* larger doses than those now recommended had a disappointing growth response. Six of them were, however, patients with hypopituitarism and a seventh was a dwarfed girl with hypoglycaemia (Case 18). We have already made the comment that these protein anabolic agents are no substitute for the growth hormone, and we may speculate as to whether some circulating growth hormone is necessary for their effective action.

We may consider, too, in what circumstances a nitrogen-retaining drug-with a much reduced androgenic component-is likely to be effective in promoting growth. We believe that there may be two such situations, one in which the total caloric intake is inadequate and the other where there is a deficiency of protein substrate. Anorexia,

\footnotetext{
* Subsequent to the completion of this survey 14 children with varying types of short stature have been treated with methandienone in doses of $0.05 \mathrm{mg} . / \mathrm{kg}$. body weight for periods varying from five to 10 months. With these small doses the height increments were $50 \%$ or more above the expected rate in only four children. Three of these four show some virilization, while no virilization occurred in the remaining 11 children. The reduction of the dose diminishes the rate of acceleration of growth, but the risk of virilization, and with it the hazard of advanced skeletal maturation, is not altogether eliminated by the use of such small doses $(0.05 \mathrm{mg} . / \mathrm{kg}$.).
}

the malabsorption syndrome, and prolonged cortisone therapy are examples of such conditions. Methandienone stimulated the appetite in eight of our children (Cases 5, 8, 12, 13, 15, 17, 19 and 23) and three of these were in the group of primordial dwarfs who seem to have appetites that are small even in relation to their size. We have, therefore, a third possible factor in growth promotion to add to the two (protein-anabolic and endocrine) already listed-that of an appetite stimulant. An increased caloric intake as occurs in obesity undoubtedly results in an increased rate of growth both in children (Wolff, 1955) and animals (Widdowson and McCance, 1960), but whether the addition of protein to a diet already adequate does so in normal children remains to be shown.

Virilization, in greater or lesser degree, occurred in all our patients, whether taking small or large doses of methandienone, and this finding confirmed the opinion that the effect of the drug in promoting growth was in part due to its androgenic action, concomitant with an equal or greater effect on skeletal maturation. As with other testosterone derivatives the virilizing effect is predominantly shown by enlargement of the phallus.

Our conclusions with regard to the use of these protein anabolic drugs such as methandienone are that they should be used in hypopituitarism, despite their disappointing effect on growth promotion; that it is safe to use them, with due precaution, where the skeletal maturation is retarded and their use is to be considered especially in 'late maturing' boys and in 'primordial dwarfs' with a retarded bone age; that sensitivity to their action varies in different individuals and in different syndromes; that they should be used for short courses and in the smallest doses shown to be effective; that the drug should be withheld in from three to six months after the start of treatment and that radiographs of epiphyseal development should be taken in a further six months before treatment is resumed.

\section{Summary}

In this study 23 children with short stature of differing aetiology were treated by methandienone in doses of 0.08 to $0.73 \mathrm{mg}$. $/ \mathrm{kg}$./day.

In 10 of these 23 children growth rates greater than those of normal children were produced.

All 23 children showed some degree of virilism and all but three an advance in skeletal maturation which correlated with or exceeded their gain in stature.

The effects of such drugs in growth promotion are complicated and difficult to define. The action of methandienone on growth promotion in the doses 
used was predominantly androgenic. In eight children the drug stimulated appetite. The protein anabolic effects of the drug could not be separated from its androgenic action.

Indications are stated for the use of such drugs in children of short stature, together with the precautions to be observed in their use.

We are grateful to Dr. A. V. Campbell, Dr. J. G. Dathan, Dr. M. E. Disney, Dr. H. Fisher, Dr. J. G. H. Frew, Dr. M. R. Green, Dr. A. C. Kendall, Dr. P. R. Kemp, Dr. R. S. MacArthur, Dr. J. C. Macaulay, Dr. M. E. MacGregor, Dr. J. C. Mole, Dr. C. Parsons, Dr. S. H. Sangster, Sir Wilfrid Sheldon, Dr. D. C. Thursby Pelham, and Dr. B. S. B. Wood, for referring some of these patients to us for investigation and treatment. Dr. R. Astley kindly assisted us with the radiological investigations.

\section{REFERENCES}

Bayer, L. M. and Bayley, N. (1959). Growth Diagnosis. University of Chicago Press, Chicago, Ullinois.
Bongiovanni, A. M. (1961). Anabolic drugs to promote growth. Pediatrics, 27, 519.

Desaulles, P. A., Krähenbühl, C., Schuler, W. and Bein, H. J. (1959) Etude expérimentale du Dianabol, un nouvel anabolisant. Schweiz, med. Wschr., 89, 1313.

Greulich, W. W and Pyle, S. I (1959) Radiographic Atlas of Skeletal Development of the Hand and Wrist, 2nd ed. Stanford Skeletal Development of the
University Press, California.

Hubble, D. (1957). Hormonal influence on growth. Brit. med. J., 1,601 .

Liddle, G. W. and Burke, H. A., Jr. (1960). Anabolic steroids in clinical medicine. Helv. med. Acta, 27, 504.

Mainland, D. (1953). Evaluation of the skeletal age method of estimating children's development. Pediatrics, 12, 114.

Mellman, W. J., Bongiovanni, A. M. and Hope, J.W. (1959). The diagnostic usefulness of skeletal maturation in an endocrine clinic. diagnostic usef
ibid., 23, 530 .

Reilly, W. A. and Gordan, G. S. (1961). Dissociation of growthstimulating and skeleton-maturing actions of the synthetic androgen, fluoxymesterone. J. Pediat., 59, 188.

Schärer, Von K., Habich, H. and Prader, A. (1960). Wachstumsförderung mit neuen anabolen steroiden. Helv. med. Acta, 27, Suppl. 39, p. 530

Widdowson, E. M. and McCance, R. A. (1960). Some effects of accelerating growth, Part I, General somatic development. Proc. roy. Soc. B, 152, 188

Wolff, O. H. (1955). Obesity in childhood. Quart. J. Med., 24, 109.

Wynn, V. and Landon, J. (1961). A study of the androgenic and some related effects of methandienone. Brit. med. J., 1, 998. 